\title{
Sea Surface Current Velocity Retrieving from TanDAM-X Satellite Data
}

\author{
Marghany, M. ${ }^{1}$ and van Genderen, J. L. ${ }^{2}$ \\ ${ }^{1}$ Department of Informatics, Faculty of Mathematics and Natural Sciences, Universitas Syiah Kuala, Jln. \\ Teuku Nyak Arief, Darussalam, Banda Aceh, Aceh, 23111, Indonesia, E-mail: magedupm@hotmail.com \\ ${ }^{2}$ Department of Earth Observation Science, Faculty of Geoinformation Science and Earth Observation (ITC), \\ University of Twente, P. O. Box: 217,7500 AE Enschede, The Netherlands, E-mail: genderen@alumni.itc.nl
} DOI: https://doi.org/10.52939/ijg.v17i4.1945

\begin{abstract}
This is the first investigation for the use of TanDEM-X data, satellite for the Malaysian coastal waters. This aims at utilizing an optimization of the Hopfield neural network to retrieve variation of sea surface current along Malaysian coastal waters. In doing so, a multi-objective evolutionary algorithm based on the Pareto front is used to minimize the error produced due to non-linearity between TanDEM-X data and sea surface movements. This work aimed at retrieving sea surface current from TanDEM-X data along the coastal waters of Malaysia. Two approaches have been implemented, the Hopfield neural network algorithm and Pareto optimal solution. The study shows that the Pareto optimal solution has a higher performance than the Hopfield neural network algorithm with a lower RMSE of \pm 0.009 . Furthermore, a Pareto optimal solution can determine the sea surface current pattern variation along the coastal water from TanDEM-X data. In conclusion, TanDEM-X data shows an excellent promise for retrieving sea surface currents.
\end{abstract}

\section{Introduction}

The complexity of ocean nature demands accurate devices and mathematical models to be comprehended. (Jingyang et al., 2001and Anderson et al., 2017) Despite the advanced technology of ocean in situ measurements, large ocean areas cannot survey with effortless. In reality, whether circumstances induce storms, which cause disasters in the coastal zone that does not allow oceanographers and researchers to acquire timeless and effortless in situ measurements (Alejandro and Saadon 1996, Alejandro and Demmler, 1997 and Jingyang et al., 2001). Recently, researchers have shown an increased interest in using remote sensing technology for ocean studies. (Li et al., 2017) Remote sensing images provide information on a large-scale ocean and also offer precise information on air-sea surface interactions (Marghany 2011a and Li et al., 2017). Besides, ocean surface features such as fronts, oil spills, and upwelling, and mesoscale eddies can be detected using remote sensing technology. ( $\mathrm{Li}$ and Zhang, 2014 and $\mathrm{Yu}$ and Yuanzhi, 2014) The microwave imaging radar is the only system with an all-weather potential to acquire measurements of airsea interaction (Romeiser and Runge, 2007 and Romeiser et al., 2010). Knowledge of sea surface currents is becoming increasingly important concerning global climate change (Anderson et al., 2017). It is well known that synthetic aperture radar
(SAR) can image the ocean surface current gradient (Romeiser et al., 2010).

Nevertheless, the imaging mechanisms are complicated since the sea surface motion variations are imaged through energy transfer toward the waves. The speculation model for the backscatter from ocean winds and currents is based on Bragg resonance between the sea surface waves and the radar microwaves. The sea surface waves that are generated by wind are imitated by a model for the wave spectrum. Since the wave spectrum is a statistical concept, huge samples prerequisite to be assimilated to deliver a constant association between wind patterns and ocean waves. Consequently, a specific spatial dimension of the ocean surface is required to contain an adequate quantity of waves. In this regard, SAR techniques for imaging sea surface current can be categorized into two approaches: (i) Doppler velocity detection, which is triggered by the movements of the SAR sensor comparative to the ocean surface dynamic, and (ii) the SAR backscatter signal which is a function of Bragg scattering. In other words, the modulation of the surface wave by an ocean current has an impact on the radar signal backscatter. Conversely, a standing location, for instance, land or islands is required for the accurate adjustment of the current quantities employing Doppler velocity approaches. Indeed, the motions of 
the sea surface on the scale of meters per second are insignificantly rivalled to the SAR sensor's movements which are approximately $7500 \mathrm{~m} / \mathrm{s}$ for RADARSAT-2 SAR (Kudryavtsev et al., 2013 and Katherine et al., 2017).

Therefore, the modulation technique is the cornerstone to understand the mechanism of SAR imaging sea surface current. In this view, the resonance practice between ocean surface waves and the radar microwave signal regularly ensues for the backscatter signal in the VV-polarization band. However, the resonance process is trivial in the VHpolarization band. Consequently, hypothetically, two-dimensional ocean surface current features and ocean winds can be retrieved mutually from dualpolarization, i.e, $\mathrm{VV}$, and $\mathrm{VH}$, which are acquired simultaneously by TerraSAR and Radarsat-2. Moreover, the VH-polarized SAR image in RADARSAT-2 dual-polarized (VV and VH) ScanSAR mode appears not to overwhelm in high wind velocity under such circumstances of the tropical cyclone. In addition, dual-polarized SAR (VV and VH) such as TerraSAR seems to be linearly correlated to the ocean wind speed. In this understanding, the C-band VH-polarized radar signal is subjugated by ocean wind, while the VV-polarized signal comprises both impacts of ocean winds and surface currents. The radar signal of VV-polarization is modulated by the surface currents across the Bragg scattering theory due to the interaction between surface Bragg waves on the scale of the radar wavelength signal and ocean surface currents (Zhang and Perrie 2018).

Needless to say, the radar backscatter of the sea surface is also can be discussed from the point of view of the action balance equation. Indeed, all information about the sea surface is contained in the wave variance spectrum or energy density, distributing wave energy over (radian) frequencies (as observed in a frame of reference moving with current velocity) and propagation directions (i.e., the direction normal to the wave crest of each spectral component). Usually, wave models determine the evolution of the action density in space and time. The action density is defined as the ratio between energy density and wave frequency and is conserved during propagation in the presence of ambient current, whereas energy density is not (Zodiatis et al., 2015). In this view, the variation of the mean current can cause shifting of the wave radian frequency. In other words, the association of depth with the current flow can induce wave refraction. This can generate high backscatter of SAR signal from the sea surface. The theory of wave action balance can be used to retrieve sea surface current in SAR data. Consistent with Inglada and Garello (2002) and Romeiser et al.,
(2014) the energy transfer between the current gradients and the waves is described by the action balance equation (ABE) which gives the nonlinear relationship between the surface current and the perturbation of the wave spectrum from its equilibrium. Several studies have been conducted to solve the action balance equation by numerical methods to compute the normalized radar crosssection (NRCS) of sea surface roughness, then utilizing the modulation model to retrieve the surface current. Nevertheless, the linearization of ABE allows generating a weak linear hydrodynamic modulation, which is involved in the problem of the relaxation rate or wave growth. Moreover, Inglada and Garello (2002) have used the Volterra series's expansion to express the nonlinear relationship between the surface current and the SAR image pixel intensity. With the Volterra model, they can compute the energy contained in the different orders (linear, quadratic and higher) and by using the inverse of the Volterra model, the sea surface current can be estimated. Marghany (2015b) addressed the question of the impact of tidal force in inducing ocean current movement. This can indicate that the ABE model cannot be used to extract sea surface current movement in the South China Sea. Conversely, Marghany (2015b) examined, two hypotheses: (i) Doppler spectra model can compute the sea surface gradient variation, and (ii) horizontal sea surface current can be retrieved from Doppler spectra variation by a computing radial component of SAR ocean current to a real ocean current.

Previous studies have demonstrated that the Bragg resonance plays a main role in the VVpolarized normalized radar cross-section NRCS, but is negligible for the VH-polarization NRCS. Moreover, the non-Bragg scattering the $\mathrm{VH}-$ polarized NRCS, but is negligible for the VVpolarized NRCS. Because the sea surface Bragg waves on the scale of the microwave radar may interact with the surface currents, the radar signal due to Bragg resonance may, therefore, be modulated by the surface currents. Moreover, the strong currents can be captured by VV-polarization backscatter, but there are almost no features in the VH-polarized backscatter (Kudryavtsev et al., 2014). Recently, Marghany (2021) developed a novel theory of ocean current features using the speculation of quantum mechanics. This theory is termed as the quantized Marghany's front, which is discovered on the east coast of Malaysia Peninsular. Further information can be obtained from Marghany (2021).

The main objective of this study is to solve the Doppler phase equation to obtain the sea surface current by using SAR data. In this paper, we have developed a method to address the question of 
retrieving ocean surface current patterns from TanDEM-X data. This is often verified by the exploitation of a neural network technique. The three hypotheses we have examined are: (i) Hopfield neural network-based mostly multi-objective optimization via the Pareto dominance algorithmic rule is executed to TanDEM-X data; (ii) multiobjective optimisation via Pareto dominance is used as procedures for eliminating inherent speckle from TanDEM-X data; and (iii); the nonlinearity of the physicist frequency shift is reduced multi-objective optimization via Pareto dominance.

\section{Data Acquisition}

Two styles of knowledge area unit needed to retrieve sea surface current parameters: TanDEM-X of SAR; (ii) and therefore, the real, unaltered sea surface current measuring throughout TanDEM-X satellite overpasses.

\subsection{Satellite Data}

A pair of Terra-SAR-X satellite data were acquired by the TanDEM-X satellite on May 62017 . The first image was acquired at 7:27:17 am while the second image was acquired at 19:20:06 pm. The data are in spotlight mode with $\mathrm{X}$-band and $\mathrm{HH}$ and VV polarization. These data are single look complex formatted data.

The TanDEM-X operational consequence involves the coordinated operation of 2 satellites flying in an adjacent configuration. The alteration constraints for the formation are: (i) the orbits ascending nodes, (ii) the angle between the perigees, (iii) the orbital eccentricities and (iv) the phasing between the satellites. The observance of ocean currents is a vital facet of assessing climate changes. Spaceborne SAR along-track interferometry (ATI) has the promise to considerably contribute to the present field. It will offer large-area, worldwide surface current measurements. In the word of Mittermayer and Runge (2003), the velocity component of moving objects may be measured with ATI. The sensitivity of the instrument principally depends on the measuring device carrier frequency and consequently the effective time lag between the two measurements administered with two antennas and receiver chains. These parameters have to be compelled to be tailored to the speed range of the objects of interest. High-speed objects like cars would like solely a really short time lag and also the two antennas acquired to be separated some meters.
The matter of mapping relatively low velocity is often resolved by formations of SAR satellites that yield sufficiently sensitive ATI measurements (Frasier and Camps 2001, Krieger et al., 2003, Romeiser and Runge 2007 and Romeiser et al., 2014). In this study, the Hopfield algorithm relies on the TanDEM-X information. The TerraSAR-X and TanDEM-X satellites transmit identical SAR instruments working at $9.65 \mathrm{GHz}$ frequency (Xband). Throughout some devoted operations, both satellites are placed associate exceedingly in a very special orbit configuration with a brief along-track baseline providing a probability for current measurements. The data utilized in this study were acquired in the StripMap mode (SM), bistatic (TS-X active / TD-X passive) mode and VV polarization. Consequently, these data have a swath width is 30 $\mathrm{km}$. Indeed, Stripmap images are typically provided comprising an area of $30 \times 50 \mathrm{~km}$. The acquisition length in Stripmap mode may be extended up to 1650 $\mathrm{km}$ (at $30 \mathrm{~km}$ width) (Gebhardt et al., 2016).

\subsection{In-situ Measurement}

Following Marghany (2017), sea surface current speed and direction are collected by Aquadopp ${ }^{\circledR}$ $2 \mathrm{MHz}$ current meter (Figure 1). Since the surface, current knowledge acquisition, the Aquadopp ${ }^{\circledR}$ $2 \mathrm{MHz}$ current meter factory-made by Nortek AS (Figure1), the Scandinavian country was used. The instrumentality could be a standalone instrumentation exploitation Doppler based technology to measure surface currents at the deployment website. The instrumentation is intended with intrinsical memory and an internal battery pack wherever it may be designed to record and store information internally for self-deployment. The Aquadopp ${ }^{\circledR} 2 \mathrm{MHz}$ current meter was deployed on the coastal water of Teluk Kemang, Port Dickson, Malaysia on May 6 2017. (Figure 2). Two phases of data collection were carried out: (i) at $6: 15$ am to $8: 15$ am and (ii) at $6: 15 \mathrm{pm}$ to $8: 15 \mathrm{pm}$. The surface current data were measured in intervals of 2 hours for both phases.

\section{Algorithms}

\subsection{Hopfield algorithm}

Marghany (2015b) has implemented Hopfield neural networks for RADARSAT-2 SAR data to retrieve sea surface current. This section has been retrieved from Marghany (2015b) work. Therefore, Hopfield neural networks are used with TanDEM-X satellite data. 


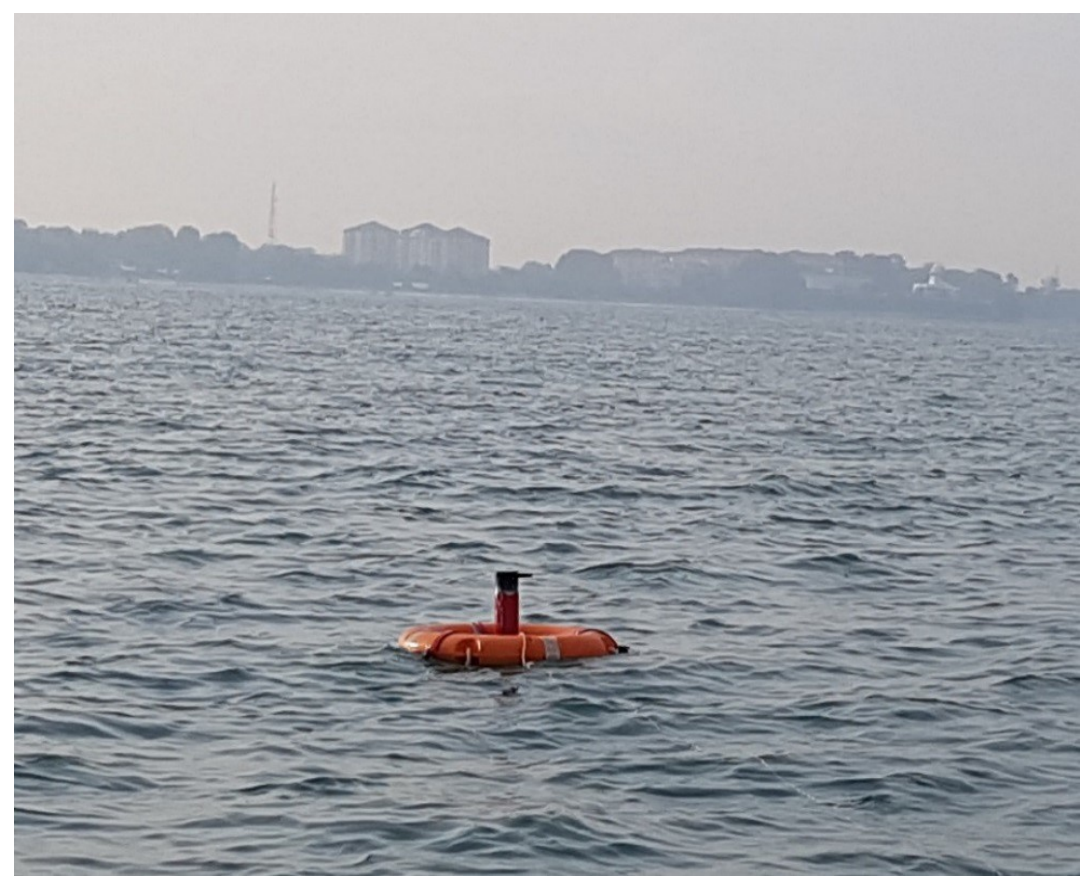

Figure 1: Aquadopp 2Mhz current meter deployment

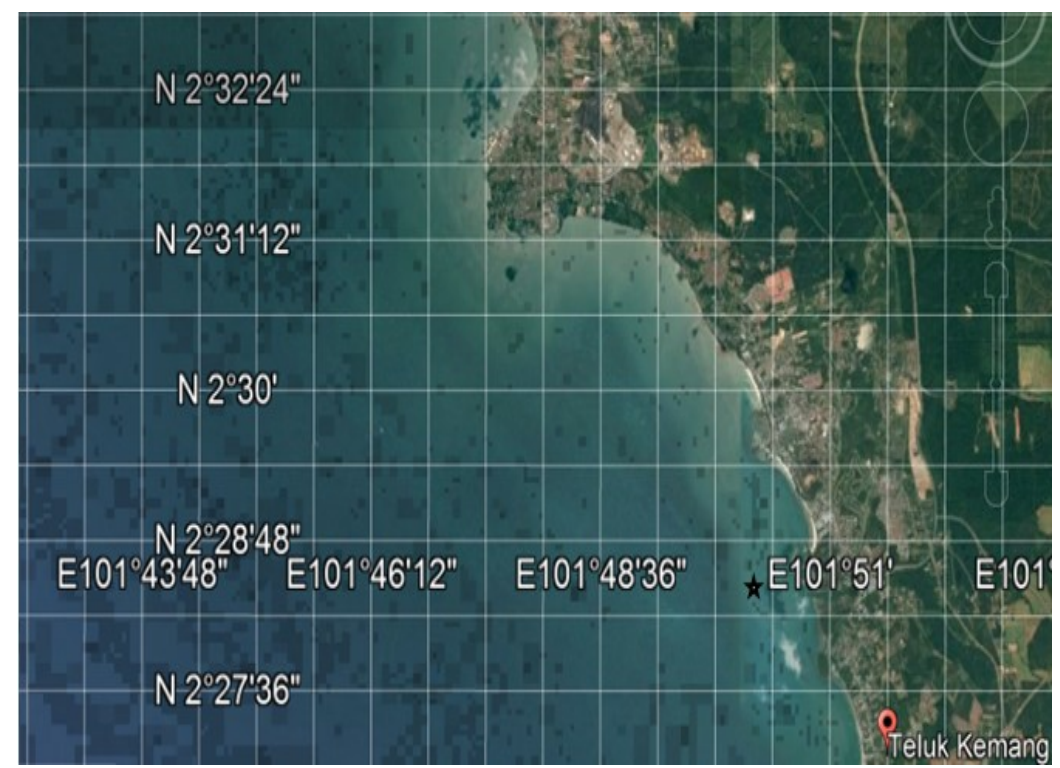

Figure 2: Geographical location of in situ measurements

Consistent with Côté and Tatnall (1997), Hopfield neural networks are considered as a promising method for determining a minimum of energy to a function (Marghany, 2011b). For instance, motion analysis and object pattern recognitions might be coded into an energy function (Cao and Wang, 2003). Furthermore, the actual physical constraint, heuristics, or prior knowledge of sea surface features, nonlinearity and the Doppler frequency shift (Marghany, 2003 and Marghany, 2004) can be coded into the energy function (Marghany, 2009a). A pattern, in the context of the $N$ node Hopfield neural network is an $N$-dimensional vector $V=\left(v_{1}, v_{2}, \ldots \ldots v_{n}\right)$ and $U=\left(u_{1}, u_{2}, \ldots \ldots u_{n}\right)$ from space $S=\{-1,1\}^{N}$. A special subset of $S$ is set of exemplar $E=\left\{e^{k}: 1 \leq k \leq K\right\}$, $e^{k}=\left(e^{k}{ }_{1}, e^{k}{ }_{2}, \ldots \ldots . ., e^{k}{ }_{n}\right)$ and $k$ is exemplar pattern where $1 \leq k \leq K$. The Hopfield net associates a vector form $S$ with an exemplary pattern in $E$. Following Marghany (2009b), Hopfield net is involved that 
$w_{i j}=w_{j i}$ and $w_{i i}=0$. Succeeding, Cao and Wang, (2003), the propagation rule $\tau_{i}$ which defines how neuron states and weight combined as input to a neuron can be described by:

$$
\tau_{i}=\sum_{j=1}^{N} f_{t}(j) w_{i j}
$$

Equation 1

The Hopfield algorithm has consisted of (i) assign weights of synaptic connections; (ii) initialize the net with an unknown pattern; and (iii) iterate until convergence and continue features tracking (Cote and Tatnall, 1997). The first step of assigning weight $w_{i j}$ to the synaptic connection can be achieved as understands:

$$
w_{i j}=\left\{\begin{array}{lll}
\sum_{k=1}^{K} e_{i}^{K} e_{j}^{K} & \text { if } & i \neq j \\
0 & & i=j
\end{array}\right.
$$

Equation 2

Hopfield neural network could be identified current pattern features by mathematical comparing to each other to build an energy function (Liang and Wang, 2000 and Arik, 2002). According to Côté and Tatnall (1997) the difference function to determine the discriminations between different features $f_{i}, f_{j}$ by a given formula:

$$
\begin{aligned}
& \operatorname{diff}\left(f_{i}, f_{j}\right)=G \cdot \max \left|\max \left(\frac{l_{i}}{l_{j}}, \frac{l_{j}}{l_{i}}\right)-L^{\prime \prime}, 0\right|+H \cdot \max \left[\min \left(\left|\theta_{i}-\theta_{j}\right|, 2 \pi-\left|\theta_{i}-\theta_{j}\right|-\theta^{\prime \prime}, 0\right]\right. \\
& \left.+J \cdot \max \mid d i s_{i j}-d i s t^{\prime \prime}, \theta\right] \mid
\end{aligned}
$$

Equation 3

where $L^{\prime \prime}$ is curvature shape of the current feature, $d i s_{i j}$ is the distance between sea surface current features $f_{i}$ and $f_{j}$, and $G$ and $H$ and $J$ are constants and $\theta$ is an angle of orientation of local curve element. In addition, dist" and $\theta^{\prime \prime}$ are the minimum acceptable distance and the maximum acceptable rotation angle, respectively before energy function.

\subsection{Pareto Algorithm}

Following Atashkari et al., (2004), Multi-objective optimization (MOB) is also termed multi-criteria optimization or vector optimization. In this regard, it has been defined as finding a vector of decision variables satisfying constraints to give acceptable values to all objective functions. Generally, it can be mathematically defined as: find the vector $S^{*}=\left[S_{1}^{*}, S_{2}^{*}, \ldots, S_{n}^{*}\right]^{T}$ to optimize:

$$
F(S)=\left[f_{1}(S), f_{2}(S), \ldots, f_{k}(S)\right]^{T}
$$

Equation 4

subject to $m$ inequality constraints:

$$
g_{i}(S) \leq 0 \quad, \quad \mathrm{i}=1 \text { to } \mathrm{m}
$$

Equation

and $p$ equality constraints:

$$
h_{j}(S)=0 \quad, \quad \mathrm{j}=1 \text { to } \mathrm{p}
$$

Equation 6

where $S^{*} \in \mathfrak{R}^{n}$ is the vector of the decision or design variables, and $F(S) \in \mathfrak{R}^{k}$ is the vector of objective functions which each of them is either minimized or maximized? However, without loss of generality, it is assumed that all objective functions are to be minimized. A point $S^{*} \in \Omega$ ( $\Omega$ is a feasible region in $\mathfrak{R}^{n}$ satisfying equations (4) and (6) is said to be Pareto optimal (minimal) concerning the all $S \in \Omega$ if and only if $F\left(S^{*}\right)<F(S)$. Alternatively, it can be readily restated as $\forall i \in\{1,2, \ldots, k\} \forall S \in \Omega-\left\{S^{*}\right\} \quad f_{i}\left(S^{*}\right) \leq f_{i}(S) \wedge$ $\exists j \in\{1,2, \ldots, k\}: f_{j}\left(S^{*}\right)<f_{j}(S)$. In other words, the solution $S^{*}$ is said to be Pareto optimal (minimal) of the ocean current pattern if no other solution can be found to dominate $S^{*}$ using the definition of Pareto dominance. For a given MOP, the Pareto front PF * is a set of the vector of objective functions which are obtained using the vectors of decision variables in the Pareto set $\mathrm{P}^{*}$, that is $\mathrm{PF}^{*}$ $=\left\{F(S)=\left(f_{1}(S), f_{2}(S), \ldots, f_{k}(S)\right): S \in \mathrm{P}^{*}\right\}$. In other words, the Pareto front $\mathrm{P} \mp$ * is a set of the vectors of objective functions mapped from $\mathrm{P}$ * (Atashkari et al., 2004 and Marghany, 2015a).

\section{Results and Discussion}

The sea surface current velocities are simulated and modelled from the TanDEM-X data spotlight with VV polarization. The simulation has been done along the range direction. The simulated velocity is taken 
across the location of The Aquadopp ${ }^{\circledR} 2 \mathrm{MHz}$ current meter (Figure 3). The test area is shown in Figure 1 which is inshore the coastal water of the Malacca Straits, Malaysia. Figure 4 shows TanDEM$\mathrm{X}$ data cross-section values increased with the increase of the incidence angle where the backscatter value is raised to $-10 \mathrm{~dB}$. The second curve is the result of the Doppler shift frequency. The curve shows that the Doppler shift frequency values fluctuated with value decreasing in the onshore $2 \mathrm{~km}$ to $5 \mathrm{~km}$. The frequency value in the nearshore area was extremely low with $0.1 \mathrm{~m} / \mathrm{s}$.
The spectral peak of the Doppler frequency is 0.04 with a range frequency of $-200 \mathrm{~Hz}$. The average Doppler shift frequency in the onshore area was 0.01 $\mathrm{Hz}$. This could be due to the low tide level of $0.3 \mathrm{~m}$ which was observed during in-situ data collection. This agrees with Marghany and Mazlan (2005). The TanDEM-X data with X-band of the spotlight product derived from the strip-map mode has been utilized in this study. Figure 4 indicates the results that are retrieved from the Hopfield rule and Pareto rule.

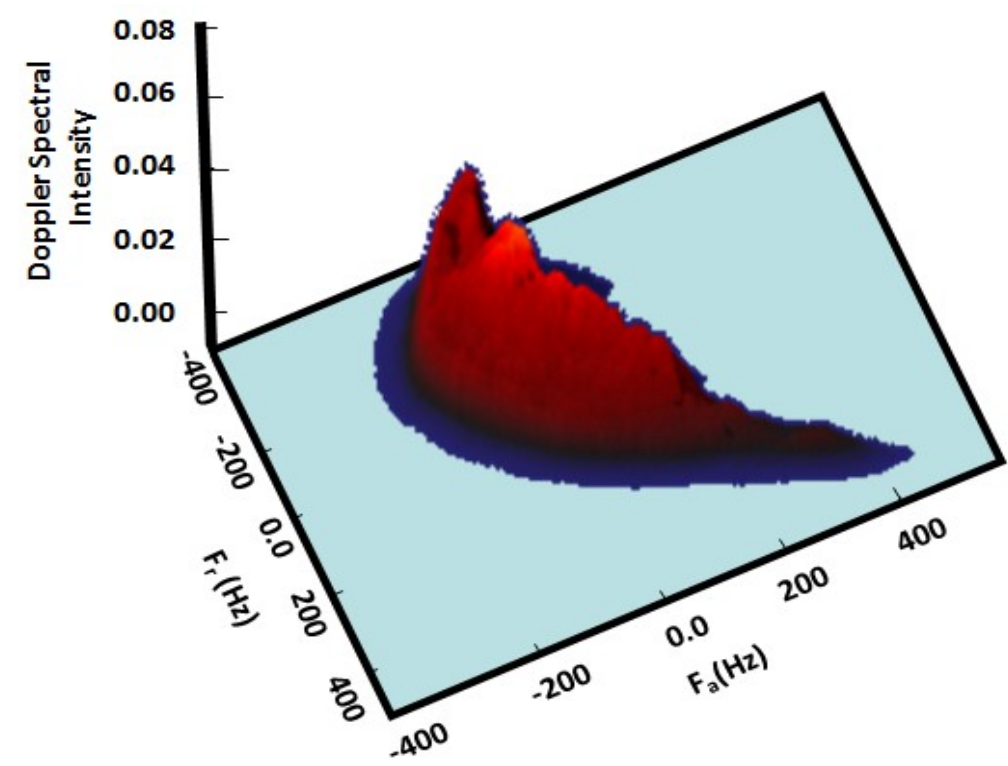

Figure 3: Doppler Spectra Intensity of TanDAM-X data

(a)

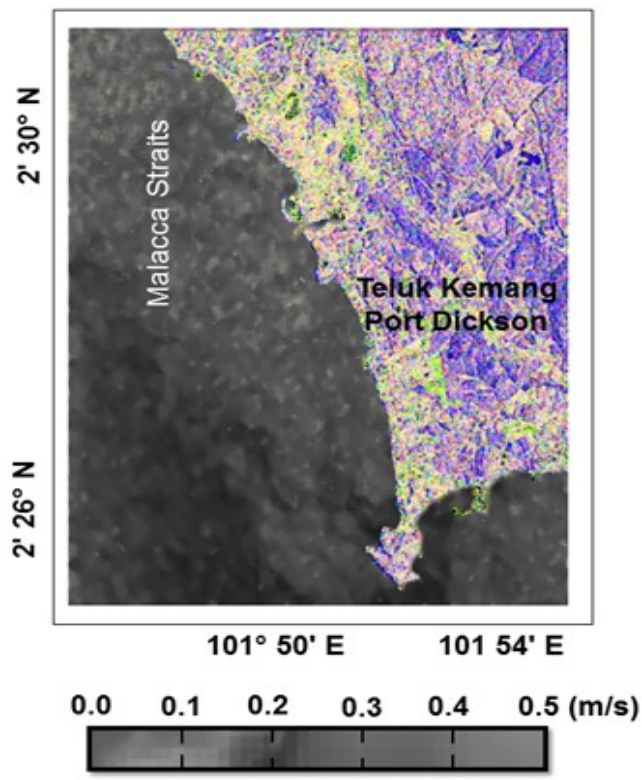

(b)

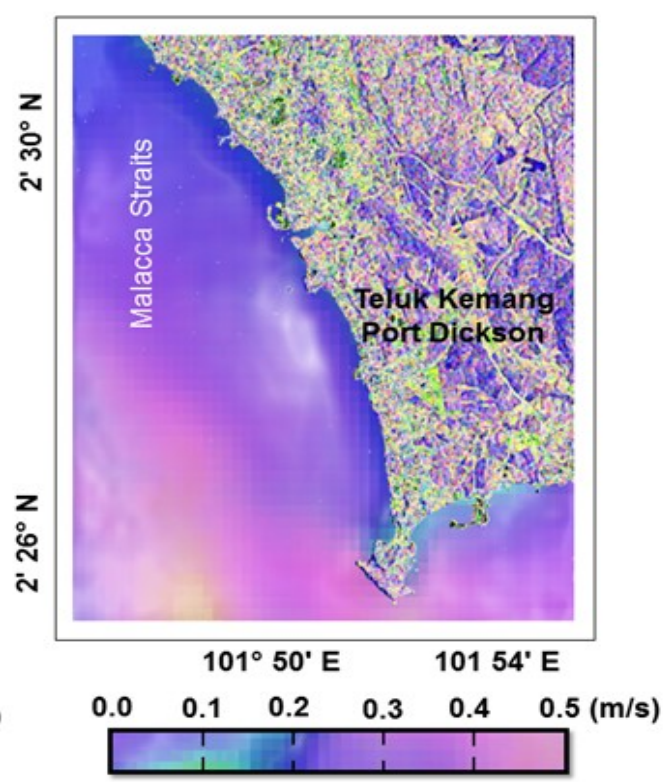

Figure 4: Ocean current pattern simulated from (a) Hopfield neural network result (b) Pareto optimal solution 


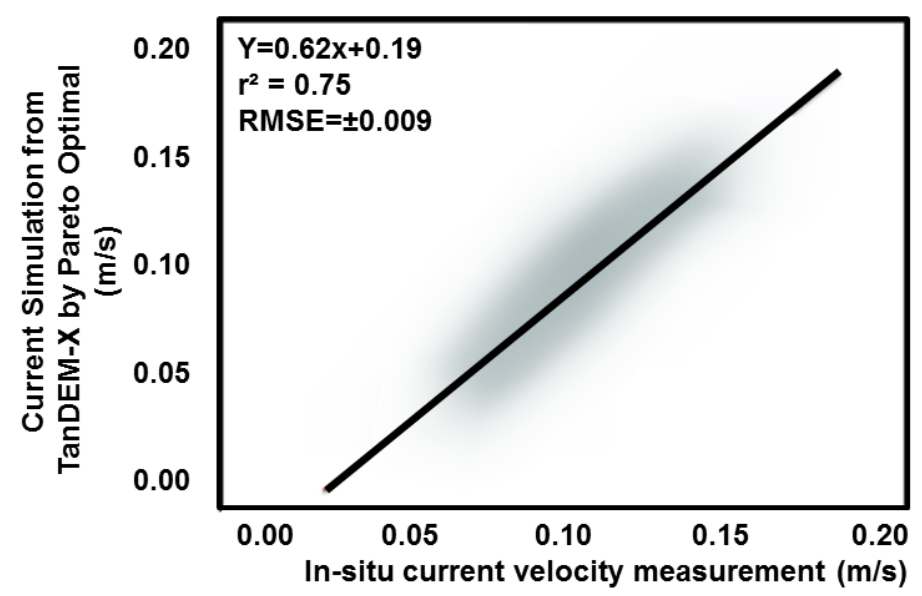

Figure 5: Significant correlation between Pareto Optimal and in situ measurements

Table 1: Statistical regression of current meter sea surface current and retrieved one by Hopfield neural network-based Pareto optimal solution

\begin{tabular}{lccc}
\hline Methods & $\boldsymbol{r}^{2}$ & RMSE $( \pm \mathrm{m} / \mathrm{s})$ & $\boldsymbol{P}$ \\
\hline $\begin{array}{l}\text { Hopfield neural network- } \\
\text { Current }\end{array}$ & 0.55 & 0.2 & 0.0071 \\
$\begin{array}{l}\text { Pareto optimal solution- } \\
\begin{array}{l}\text { Current meter } \\
\text { M }\end{array}\end{array}$ & 0.75 & 0.009 & 0.000076
\end{tabular}

It is attention-grabbing to realize that Pareto algorithmic rule has found the most effective solution from the sea surface current pattern as compared to Hopfield neural network (Figure 4b). The morphology of ocean surface current structures is a well-known exploitation Pareto algorithmic rule. Indeed, random generation of 1000 iterations at intervals of $3 \mathrm{~min}$ are needed to realize the performance of the Pareto algorithmic program. The Pareto algorithm delivered a spatial variation of surface current from onshore to offshore. Onshore surface current is dominated by the maximum value of $0.12 \mathrm{~m} / \mathrm{s}$ while the offshore surface currents have a maximum value of $0.2 \mathrm{~m} / \mathrm{s}$, which agrees with the study of Alejandro and Saadon (1996).

Figure 5 shows significant correlations between the result of sea surface current velocities which were simulated from TanDEM-X data and the result extracted in the in-situ measurement. Figure 5 illustrates how the correlation coefficient changes as the linear relationship between the two variables are altered. While in regression the emphasis is on predicting one variable from the other, in correlation the emphasis is on the degree to which a linear model may describe the relationship between two variables. There is a good relationship between the two variables with $\mathrm{r}^{2}$ of 0.75 . However, this relationship is not perfect, but seems to have a positive linear relationship, and corresponds to what one would expect when considering two variables correlated and following the assumption of normality. Table 1 delivers the accuracy of this study. The Pareto optimal solution has an excellent performance than the Hopfield algorithm, with a lower $P$-value of 0.00006 and RMSE of \pm 0.009 and the highest $r^{2}$ of 0.75 (Table 1). The rate of RMSE is generated due to Doppler frequency shift which caused nonlinearity between ocean surface current and TanDEMX data. However, a Pareto optimal solution has improved the accuracy of this study as it found the best optimal value for retrieving sea surface current from TanDEMX SAR data.

In term of accuracy, this study confirms the work done by Frasier and Camps 2001, Kudryavtsev et al., (2013) and Kudryavtsev et al., 2014, that VVpolarization is an appropriate channel for retrieving sea surface current from the SAR images. The accuracy of this work can be improved in the future based on the physical parameters of the Hopfield algorithm and also by using sequences of the TanDEM-X SAR data. In fact, on some occasions, the weak current can affect the accuracy of the algorithm. The fluctuation dynamic current flows are required to improve the accuracy and this can be achieved by acquiring sequences of TanDEM data. Consistent with Marghany and Mansor (2016) and Marghany (2017), the Hopfield neural network is anticipated as an optimization tool to reduce the 
impact of Doppler nonlinearity in the SAR data. Subsequently, a multi-objective optimization is fairly deliberated as attaining a vector of verdict variables satisfying constraints to offer precisely to all objective functions. This confirms the study of Marghany and Mansor (2016).

Additionally, the multi-objective optimization via Pareto dominance acquires a particular curve that reduces the inconsistency between the certain ocean surface current from TanDEMX data and in situ measurements. In this understanding, the new approach supported TanDEMX data and as a result of the multi-objective optimization via Pareto Dominance, know how to minimize the number of the residual faults for retrieving ocean surface current from TanDEMX data and delivers precise ocean surface current pattern spatial variation. This work recommends the work done by Atashkari et al., (2014) and Marghany (2015b). Moreover, it is suggested to exploit the time series of TanDEMX satellite data for watching the daily coastal current and its seasonal variations. With the advent of new SAR instrument systems, such as TanDEM-X data, dual- and quad-polarization SAR data are now made available, to possibly yield more useful information than conventional single-polarization SAR observations. This can help to possibly go beyond the present geophysical retrieval algorithms in other ocean or sea areas.

\section{Conclusions}

This work initiated a new approach for sea surface current studies along Malaysian coastal waters. This is the first experimentally operated TanDEM-X satellite not only in Malaysia but in all the Southeast Asian coastal waters. Two approaches are prescribed: (i) Hopfield neural network rule; and (ii) Pareto optimum resolution. The study shows that the Pareto optimum resolution has a higher performance than the Hopfield neural network rule with the lowest RMSE of \pm 0.009 . Further, the Pareto optimum resolution can verify the ocean surface current pattern variation using TanDEMX data. In conclusion, TanDEMX data reveal a superb guarantee for retrieving ocean surface current with $\mathrm{X}$-band with VV polarization.

\section{References}

Alejandro, C. and Saadon, M. N., 1996, Dynamic Behaviour of the Upper Layers of the South China Sea. Proceedings of the National Conference on Climate Change,12-13 August 1996, Universiti Pertanian Malaysia, Serdang. 135-140.
Alejandro, C. and Demmler, M. I., 1997, Winddriven Circulation of Peninsular Malaysia's Eastern Continental shelf. Sci. Mar., Vol. 61(2), 203-211.

Anderson, K., Ryan, B., Sonntag, W., Kavvada, A. and Friedl, L., 2017, Earth Observation in Service of the 2030 Agenda for Sustainable Development. Geo-spatial Information Science, Vol. 20(2), 77-96, DOI: 10.1080/1009520.2017.1333230.

Arik, S., 2002, A Note on the Global Stability of Dynamical Neural Networks. Circuits and Systems I: Fundamental Theory and Applications, IEEE Transactions on, Vol. 49, 502-504.

Atashkari, K., Nariman-Zadeh, N., Darvizeh, A., Yao, X., Jamali, A. and Pilechi, A., 2004, Genetic Design of GMDH-type Neural Networks for Modelling of Thermodynamically Pareto Optimized Turbojet Engines. WSEAS Transactions on Computers, Vol. 3(3), 719-724.

Cao, J. and Wang, J., 2003, Global Asymptotic Stability of a General Class of Recurrent Neural Networks with Time-Varying Delays. Circuits and Systems I: Fundamental Theory and Applications, IEEE Transactions on, Vol. 50, 3444.

Cote, S. and Tatnall, A., 1997, The Hopfield Neural Network as a Tool for Feature Tracking and Recognition from Satellite Sensor Images. International Journal of Remote Sensing, Vol. 18, 871-885.

Frasier, S. J. and Camps, A. J., 2001, Dual-Beam Interferometry for Ocean Surface Current Vector Mapping. IEEE Transactions on Geoscience and Remote Sensing. Vol. 39(2), 401-14.

Gebhardt, C., Pleskachevsky, A., Rosenthal, W., Lehner, S., Hoffmann, P., Kieser, J. and Bruns, T., 2016, Comparing Wavelengths Simulated by the Coastal Wave Model CWAM and TerraSARX Satellite Data. Ocean Modelling, Vol. 103, 133-144.

Inglada, J. and Garello, R., 2002, On Rewriting the Imaging Mechanism of Underwater Bottom Topography by Synthetic Aperture Radar as a Volterra Series Expansion. IEEE Journal of Oceanic Engineering, Vol. 27, 665-674.

Jingyang, B., Dingbo, C. and Jiancheng, Li., 2001, A Preliminary Study on the Establishment of Ocean Tide Models Over the South China Sea from T/P altimetry. Geo-spatial Information Science, Vol. 4(4), 19-24, DOI: 10.1007/BF02-826573.

Krieger, G., Fiedler, H., Mittermayer, J., Papathanassiou, K. and Moreira, A., 2003, Analysis of Multistatic Configurations for spaceborne SAR Interferometry. IEE 
Proceedings-Radar, Sonar and Navigation, Vol. 150(3), 87-96.

Kudryavtsev, V. N., Chapron, B., Myasoedov, A. G., Collard, F. and Johannessen, J. A., 2013, On Dual Copolarized SAR Measurements of the Ocean Surface. IEEE Geoscience and Remote Sensing Letters. Vol. 10(4), 761-765.

Kudryavtsev, V., Kozlov, I., Chapron, B. and Johannessen, J. A., 2014, Quad-Polarization SAR Features of Ocean Currents. Journal of Geophysical Research: Oceans, Vol. 119(9), 6046-6065.

Liang, X. B. and Wang, J., 2000, Absolute Exponential Stability of Neural Networks with a General Class of Activation Functions. IEEE Transactions on Circuits and Systems I: Fundamental Theory and Applications, Vol. 47, 1258-1263.

Li, Y. and Zhang, Y., 2014, Synthetic Aperture Radar Oil Spills Detection Based on Morphological Characteristics. Geo-spatial Information Science, Vol. $17(1), 8-$ 16, DOI: 10.1080/10095020.2014.883109.

Li, D., Wang, M., Dong, Z., Shen, X. and Shi, L., 2017, Earth Observation Brain (EOB): An Intelligent Earth Observation System, Geospatial Information Science, Vol. 20(2), 134140, DOI: 10.1080/10095020.2017.1329314.

Marghany, M., 2003, Utilization of Hopfield Neural Network and Quasi-linear Model for Longshore Current Pattern Simulation from RADARSAT. CD-ROM Proceeding of IGARSS'2003, 20-25 July, Toulouse, France. 1-3.

Marghany, M., 2004, Neural Network for Surface Current Trajectory Modelling from RADARSAT-1 SAR Data. Proceeding of $25^{\text {th }}$ Asian Conference 22- 26 November 2004. Sheraton Chiang Mai Hotel, Chiang Mai, Thailand. Vol. 1, 362-366.

Marghany, M., 2009a, Robust Model for Retrieval Sea Surface Current from Different RADARSAT-1 SAR Mode Data. 2009 IEEE International Conference on Signal and Image Processing Applications, 492-495.

Marghany, M., 2009b, Volterra - Lax-wendroff Algorithm For Modelling Sea Surface Flow Pattern from Jason-1 Satellite Altimeter Data. Lecture Notes in Computer Science (including subseries Lecture Notes in Artificial Intelligence and Lecture Notes in Bioinformatics). Volume 5730 LNCS, 1-18.

Marghany, M., 2011a, Developing Robust Model for Retrieving Sea Surface Current from RADARSAT-1 SAR Satellite Data. International Journal of Physical Sciences, Vol. 6, 6630-6637.
Marghany, M., 2011b,Three-Dimensional Coastal Water Front Reconstruction from RADARSAT-1 Synthetic Aperture Radar (SAR) Satellite Data. International Journal of the Physical Sciences, Vol. 6(29), 6653-6659.

Marghany, M., 2015a, Flock 1 Data Multi-Objective Evolutionary Algorithm for Turbulent Flow Detection. CD of 36th Asian Conference on Remote Sensing (ACRS 2015), Manila, Philippines, 24-28 October 2015. a-a-rs.org/acrs/administrator/components/com.../files/ .../TH1-5-2.pdf.

Marghany, M., 2015b, Simulation Sea Surface Current from RADARSAT-2 SAR Data Using Hopfield Neural Network. 2015 IEEE 5th AsiaPacific Conference on Synthetic Aperture Radar (APSAR). 805-808. DOI:10.1109/APSAR.2015.7306326.

Marghany, M. and Mansor, S., 2016, Retrieving of Sea Surface Current Variations from Sentinel-1A Satellite Data. CD of 37th Asian Conference on Remote Sensing (ACRS), 37th ACRS from 17th - 21st October 2016, Galadari Hotel,Colombo,Sri Lanka, 1-6.

Marghany, M., 2017, Sea Surface Retrieving from TanDEM-X Satellite Data. Proceedings of 38th Asian Conference on Remote Sensing (ACRS),New Delhi, India, www.a-a-r s.org/acrs/administrator/components/com_jresea rch/files/.../689.pdf [Acess on March 12 2018].

Marghany, M., 2021. Nonlinear Ocean Dynamics: Synthetic Aperture Radar. Elsevier.

Mittermayer, J. and Runge, H., 2003, Conceptual Studies for Exploiting the TerraSAR-X Dual Receive Antenna. International Geoscience And Remote Sensing Symposium, Vol. 3, III-2140.

Romeiser, R. and Runge, H., 2007, Theoretical Evaluation of Several Possible Along-Track InSAR Modes of TerraSAR-X for Ocean Current Measurements. IEEE Transactions on Geoscience and Remote Sensing, Vol. 45(1), 2135.

Romeiser, R., Suchandt, S., Runge, H., Steinbrecher, U. and Grunler, S., 2010, First Analysis of TerraSAR-X Along-Track InSAR-derived Current Fields. IEEE Transactions on Geoscience and Remote Sensing, Vol. 48(2), 820829.

Romeiser, R., Runge, H., Suchandt, S., Kahle, R., Rossi, C. and Bell, P. S., 2014, Quality Assessment of Surface Current Fields from TerraSAR-X and TanDEM-X Along-Track Interferometry and Doppler Centroid Analysis. IEEE Transactions on Geoscience and Remote Sensing, Vol. 52(5), 2759-2772. 
Zhang, G. and Perrie, W., 2018, Dual-Polarized Backscatter Features of Surface Currents in the Open Ocean during Typhoon Lan (2017). Remote Sensing, Vol. $10(6)$, 875. DOI: $10.3390 /$ rs 10060875 .
Zodiatis, G., Galanis, G., Kallos, G., Nikolaidis, A., Kalogeri, C., Liakatas, A. and Stylianou, S., 2015, The Impact of Sea Surface Currents in Wave Power Potential Modeling. Ocean Dynamics. Vol. 65(11), 1547-1565. 